\title{
Human Myiasis in Neonates and Children of the Niger Delta Wetlands and South-East Nigeria
}

\author{
Ogugua Kasiemobi Ogbalu', Ted George Achufusi ${ }^{2}$, Eme Efiowan Orlu ${ }^{1}$, Dorcas Sauta Bawo ${ }^{3}$, \\ Chika Harriet Adibe ${ }^{4}$, Lekia Kumbe ${ }^{1}$, Obioma Azuonwu ${ }^{5}$, Emmanuel Amadi ${ }^{1}$
}

\begin{abstract}
${ }^{1}$ Applied and Environmental Biology, Rivers State University of Science and Technology, Port Harcourt, Nigeria; ${ }^{2}$ New York College of Osteopathic Medicine, New York, USA; ${ }^{3}$ Department of Biological Sciences, Niger Delta University, Amassoma, Nigeria; ${ }^{4}$ National Primary Health Care, Enugu, Nigeria; ${ }^{5}$ Department of Medical Laboratory Sciences, Rivers State University of Science and Technology, Port Harcourt, Nigeria.

E-mail: ogbaluo@yahoo.com
\end{abstract}

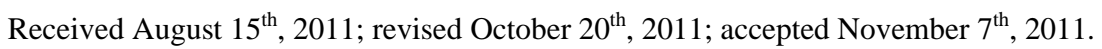

\begin{abstract}
Background: Myiasis is characterized by larval infestation of body tissues or cavities of living hosts. Although most frequently observed in underdeveloped and tropical countries, reports of human myiasis have been encountered throughout the world including temperate zones. Cases of human myiasis in Nigeria and most African countries are most probably under-reported because many remain undiagnosed, unidentified or unpublished. We had conducted studies on myiasis earlier in 2006. Here we conducted preliminary studies in 2009 and we undertook the main studies between January and December 2010. Objectives: We assessed the infection rates of neonates and children of two ecological zones in Nigeria [Niger Delta and South-East]. Patients and Methods: We studied a cohort of 400 patients presenting different cases of myiasis in children within the age bracket 0 - 12 years. We extracted maggots from different parts of neonates, toddlers and children and our therapeutic approach was the application of cholesterol-free oil for extraction and the use of antibiotics to seal up the openings of wounds. Results: Dermatological data showed in neonates an overall infection rate of 16\% in Enugu state [CI 95\%, 15.2 - 16.2]; 4\% in Anambra [CI 95\%, 3.4 - 4.7]; 7\% in Abia State [CI 95\%, 6.1 - 7.4]; 11\% in Imo [CI 95\%, 10.3 - 11.7]; 20\% in Ebonyi [CI 95\%, 18.4 - 21.6]; 7\% infection in Rivers [CI 95\%, 6.8 - 7.8]; 17\% in Bayelsa [16.1 - 17.5] and 18\% in Akwa Ibom [CI 95\%, 17.7 - 18.8]. Based on their sites of infection, five different types of myiases were diagnosed in neonates and children of the Niger Delta and South-East zones of Nigeria.
\end{abstract}

Keywords: Human Myiasis, Neonates, Children, Nigeria, Infection Rates, Treatments

\section{Introduction}

Myiasis-causing agents are found in different zones of Nigeria especially in the humid areas. Extensive studies on the epidemiology of Cordylobia anthropophaga in the Niger Delta have been established. Flies of different families are associated with cases of human myiasis as well as other animals and they include Calliphoridae, Sarcophagidae, Oestridae, Fanniidae, Muscidae, Stratiomyidae and Phoridae. Infestation of the skin and subcutaneous is caused by the larvae of obligatory dipterous insects. Maggots of the aforementioned families penetrate skins of infants causing injuries in them. Earlier we had established myiasis in women and infants of the rural areas of the Niger Delta of Nigeria. In the present study our objective was to assess the skins of the neonates and children who are exposed to the contaminated environments and examine other parts of their bodies for myiasis agents. Reports are available on the world wide distribution of myiasis-causing flies, ranging from North Africa of Saudi Arabia [1] to West Africa of Nigeria; [2] to New Zealand [3] up to Europe, Latin America and USA.

Although cases of $D$. hominis myiasis are primarily cutaneous, there are a number of records of ophthalmomyiasis [3]. In some cases, the larvae may burrow into deeper tissues causing severe symptoms: deaths from larvae burrowing through the fibrous portion of the fontanelle of neonates have been reported. Most derma- 
tological data that would have provided information on types of myiasis-causing agents, numbers of maggots extracted per patient etc are not available in most Nigerian hospitals.

Myiasis has become a common phenomenon in most parts of Nigeria especially in the rural areas of the Niger Delta wetlands and South-East where we carried out the study. Most reports available on the incidences of myiases favoured mainly adults and a few records are available on myiasis in children in Nigeria. Oral and cutaneous myiases in infants of the Niger Delta had been reported [2]. Reports from other workers on myiasis from travelers are also available [4]. In the early twenties and thirties people with skin maggots were dumped inside the evil forests as abominators; people viewed the presence of maggots in the skin as evil and disgrace to the community where the children were born.. Other predisposing factors for larval infestation in children include dirty habits like sucking of fingers and toes, kissing of pets [cats and dogs]. Contacts with infected domestic animals such as pets that harbor eggs of $C$. anthrophaga which are tucked on their hair are other sources of myiasis- causing agents.

With reports on the presence of maggots in the breasts of some rural nursing mothers [1] and even in old women breast it becomes more burdensome to observe maggots in children who have tender skin; vulnerable to piercing by the maggots that are equipped with powerful mouth hooks that are adapted for tearing skins. In order to assess the prevalence of human myiasis in children visits were made to rural areas within each state sampled in the two ecological zones of Nigeria.

\section{Patients and Methods}

The patients' population consisted of neonates, toddlers and children whose ages ranged from 0 - 12 years. They were 400 patients with 50 drawn from eight states of the two ecological zones; Niger Delta and South-East. The two zones were selected based on the fact that there were health issues on the presence of lesions and maggots in the skins of children. The zones were different from each other; their terrains, humidity, temperature, rainfall and vegetation are not similar. Neonates, infants and children in some selected states of the two zones were examined. A Table of random numbers was used to assign numbers to any particular community that reported of myiasis; families that picked positive numbers 1 - 50 were selected and children there were examined for myiasis. Skins of the aforementioned children were examined for boil-like lesions and maggots where present were extracted using forceps after applying a drop of cholesterolfree oil. Antibiotics were applied to the opening to prevent infections.

\subsection{Sampling Procedure/Extraction}

Samples were taken from each state capital and a rural community. Children of ages $0-12$ were examined for myiasis. Different parts of their body were examined and number of boil-like lesions [furuncles] was examined for myiasis-causing agents. We randomly examined fifty children per city [neonates inclusive] and fifty per village in the eight respective states studied: Rivers, Bayelsa, Imo, Abia, Enugu, Akwa Ibom, Ebonyi and Anambra states of Nigeria. We carried out a sampling plan that covered from January to December 2010.

After establishing the areas to be sampled based on reports from endemic regions, enquiries were made of homes with newborn babies and children within the age bracket [0 - 12 years]. Using a table of random numbers, numbers 1 - 50 were distributed along with other numbers from $51-100$ and families that picked the positive numbers 1 - 50 were selected for examination of children. Samplings were restricted to Saturdays to ensure that children were available at home and sampling time was and as early as 7 am to be able to meet with parents and get their permission and presence for the exercise. Most parents did not allow photographs of their children to be taken especially when maggots were extracted. Some insisted that money be paid prior to extraction. Different parts of the bodies of children were examined noting those that are living with pets and noting type of pet care. Apart from age, the number of larvae extracted per furuncle was recorded. Data were also collected from pets.

\subsection{Extraction of Larvae}

In the rural areas of Nigeria, the first step that is usually taken is to drop palm oil into the opening of the boil and allow some seconds for the suffocating larva to wriggle up to the surface for air. It is usually at this point that the thumb and the first finger are placed around the furuncle and pressed [press as if one is pressing a pimple; administer just a little but firm pressure] to force the larva out. However in this study we applied a drop of cholesterol-free oil [Laser oil] which is not as heavy as palm oil but allows easier movement of the larvae within the cavity. Manual extraction was done with the aid of a pair of forceps. More than $94 \%$ of rural people interviewed in Niger Delta extracted maggots from the skin manually using their fingers [ $\mathrm{n}=250$ patients].

\subsection{Antibiotics}

After extraction, a fluidy substance normally oozes out from the cavity where the maggot had been squeezed out. This is the serosanguinous fluid and a cotton wool absorbed in ivermectin was used in cleaning out the cavity. The antibiotic was then applied and squeezed into the 
cavity and used to seal up the cavity.

\section{Data Analysis}

Statistical analyses were performed using SPSS software. A Z-test of means was used to determine whether the mean number of maggots collected differed significantly between the two ecological zones. Paired t-test was used to assess the significant difference between the number of maggots collected from the two zones. Pie charts were also used to show proportional distribution of data collected on the number of maggots in neonates, toddlers and children in different states.

\section{Results and Discussion}

\subsection{Epidemiology/Population of Maggots of $C$. anthropophaga in Different Localities of Niger Delta and South-East Nigeria during the Dry and Rainy Seasons}

Infestation of $C$. anthropophaga occurred during rainy and dry seasons of the year. However, infestation in both Niger Delta region and South-East states were higher during the rainy season hence the number of maggots extracted from April through October was high and lowest in August 2010 (Figure 1). Usually a brief period of dryness is witnessed in August in the two zones during the year. Flies and larvae recovered were C. anthropophaga although we also collected some Lucilia spp maggots from some neonates and children. Figure 1 shows the number of maggots extracted from different localities sampled in the two regions. Generally myiasis infection was higher during the rainy seasons in Nigeria. However infection in travelers will depend on the precautionary measures embarked on by the visitors; people who dwell in the endemic regions that are cautious about their lifestyles and hygiene have never been victims except in accidental cases. The number of maggots extracted in the states of the Niger Delta far exceeded those of the South-East states (Figure 2). The highest number was obtained from Bayelsa [191.2] followed by Rivers [158.4] and Akwa Ibom [116.4]. Data on the number of Cordylobia maggots from the three Niger Delta states were significantly higher than those collected from the eastern states [t-test, $\mathrm{p}<0.05$ ]. The Niger Delta zone is a humid environment and the lifestyles of the rural dwellers predispose them to myiasis agents. In the eastern zones they are predominantly farmers and traders. The eastern states are drier with less hydrological implications and therefore less infestation.

\subsection{Infection Rates of $C$. anthropophaga}

Dermatological data showed in neonates an overall infection rate of $16 \%$ in Enugu State [CI 95\%, 15.2 - 16.2];

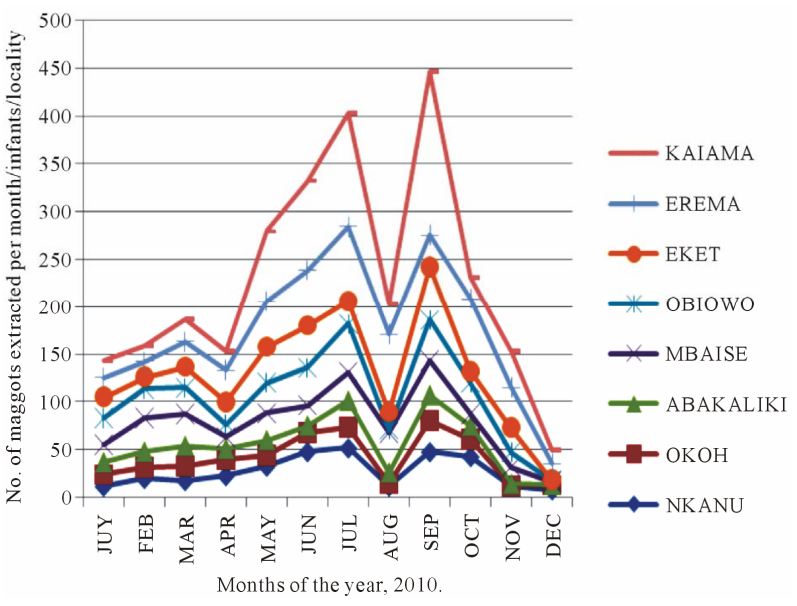

Figure 1. Epidemiology of $C$. anthropophaga in the localities of Niger Delta and South-East states of Nigeria.

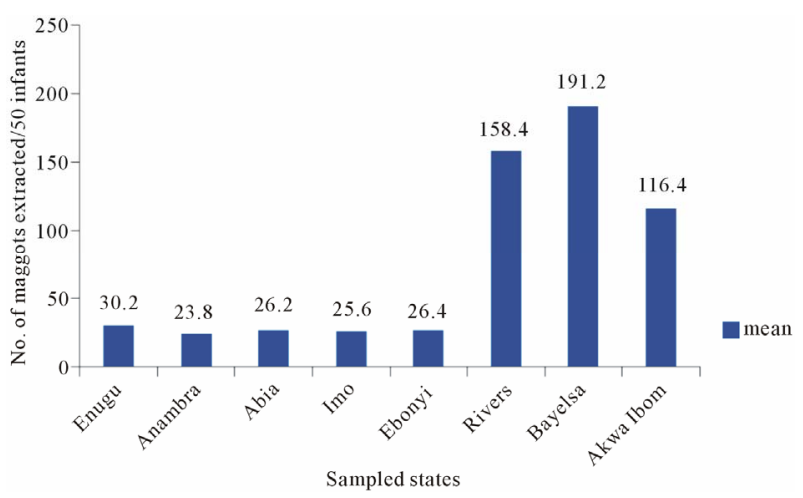

Figure 2. Mean number of $C$. anthropophaga maggots extracted from infants of the Niger Delta and South-East states of Nigeria.

4\% in Anambra [CI 95\%, 3.4 - 4.7]; 7\% in Abia State[ CI 95\%, 6.1 - 7.4]; 11\% in Imo[CI 95\%, 10.3 - 11.7]; 20\% in Ebonyi [CI 95\%, 18.4 - 21.6]; 7\% infection in Rivers [CI 95\%, 6.8 - 7.8]; 17\% in Bayelsa [16.1 - 17.5] and 18\% in Akwa Ibom [CI 95\%, 17.7 - 18.8].

The availability of patients with human myiasis in different parts of the Niger Delta and South-East is a proof of a gradual but rampart spread of the disease. Many infants and children especially in the endemic rural areas were found either with infection or with a scar of myiasis in one part of their body or the other. The dermatological data showed differential infection rates in neonates, toddlers and children (Figures 3(a)-(c)). Most of the infections in the neonates were due to C. anthropophaga.

\subsection{Sites of Infection}

Based on their sites of infection, five different types of myiases were diagnosed (Figure 4). Figure 5 showed parts of the body of children and number of maggots of $C$. anthropophaga extracted. Other sources of infection on 


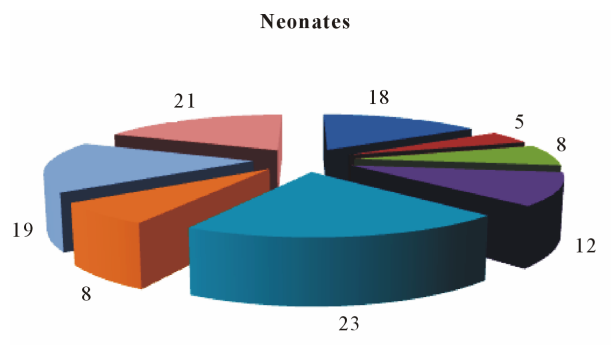

(a)

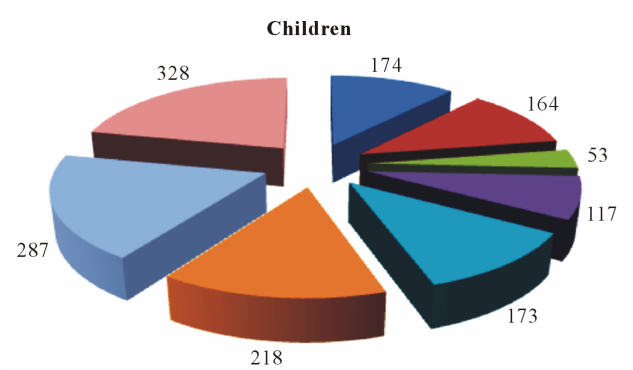

(b)
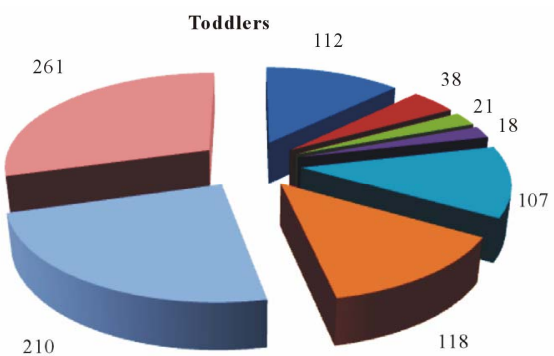

(c)

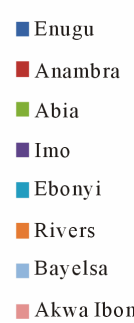

Enugu

- Anambra

abia

- Imo

Ebony $\mathrm{i}$

a Rivers

Bayelsa

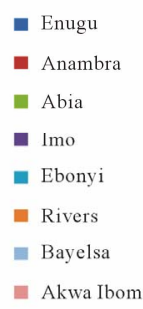

- Akwa Ibom

Figure 3. Impact of human myiasis in different groups of children in Niger Delta and South-East states of Nigeria.

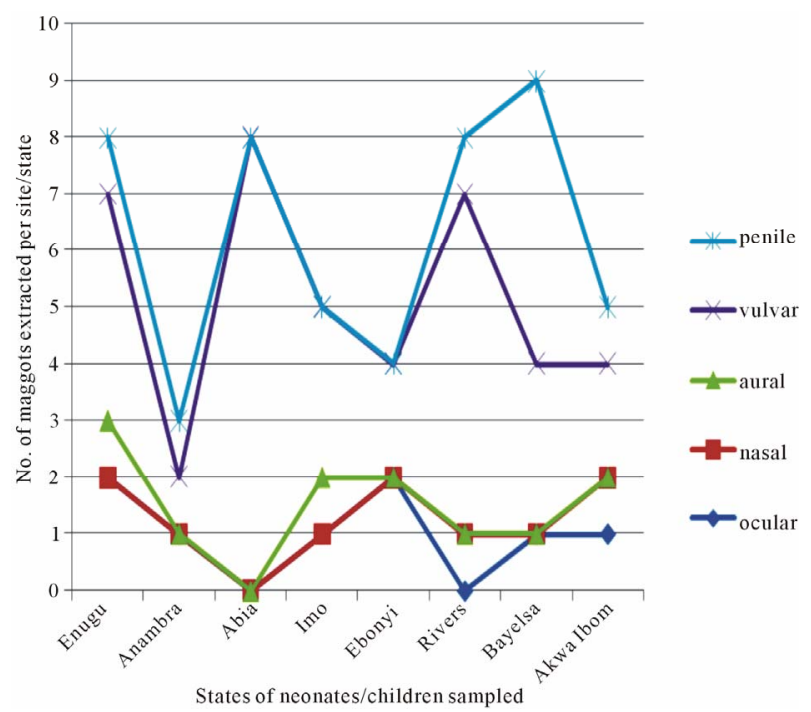

Figure 4. Types of myiasis in children of Niger Delta and South-East states of Nigeria.

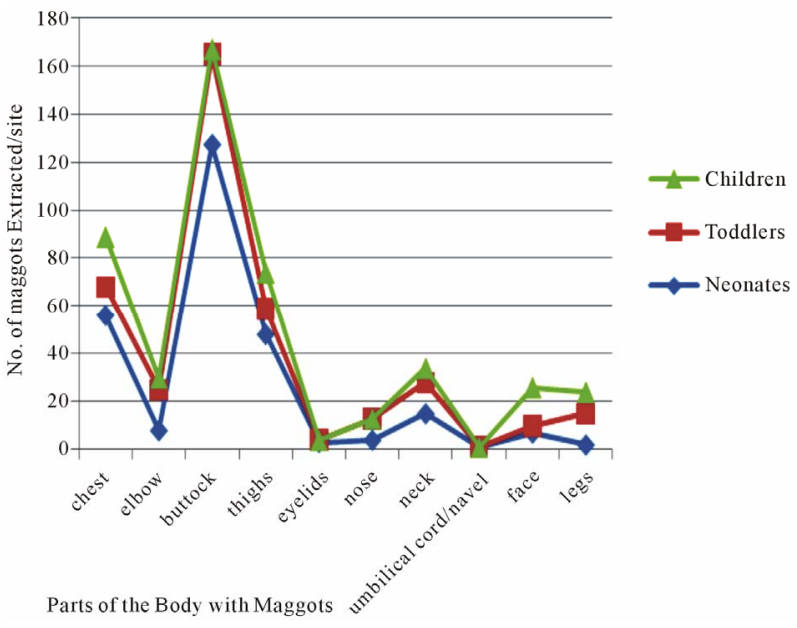

Figure 5. Other parts of the body/number of maggots extracted.

the buttocks included the use of recycled diapers; they were sun-dried and re-used [possibly with Cordylobia eggs] due to poverty. This was also part of the reason for vulvar and penile myiasis in babies from the rural environments. On one of the sampling dates one first instar larva of $C$. anthropophaga was observed in the umbilical cord of a two-day-old neonate. The umbilical cord had some foul odour showing a septic infection; the offensive odour might have attracted gravid females that deposited eggs on the exposed infected cord or the larva gained entry through the soiled wrapper that they used in covering the babies [which might have contained eggs that hatched on the umbilical cord]. Some babies were delivered at home in the rural settings with untrained women attending to the women in labor and also handled neonates with unsterilized instruments. Again, the use of unsterilized scalpels and razor blades, to cut the umbilical cord and the use of recycled bandage to wrap the umbilical cord at delivery are other sources from where the maggots entered the neonatal system. Some adopted the use of unclean towels, wrappers in wiping blood at delivery in some of the rural settings in Nigeria. In some cases they applied the leaves of plants, Bryophyllum spp on the umbilical cord, one of the plants we observed with $C$. anthropophaga eggs. Other authors had reported on neonatal myiasis. A report was given of an orphan, a female neonate abandoned in a dustbin in India $[5,6]$ gave a case report of a 12-day-old female neonate infected with Lucilia spp. Also a report was given on maggot infestation in wounds of injured soldiers [7]. The highest incidence of penile myiasis was recorded in Bayelsa where we recorded 9 maggots in 8 neonates. Generally in most rural settings after circumcision, the wounds were left open to dry. Figure 5 shows that the buttocks of neonates, toddlers and children sustained higher number of maggots; 


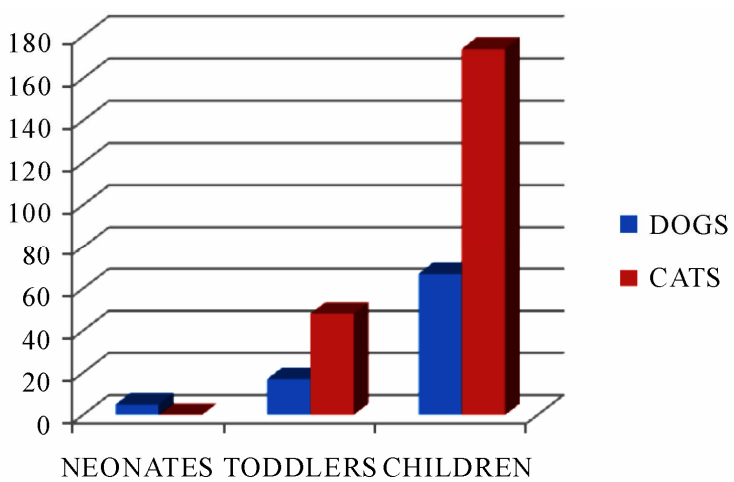

Figure 6. Number of $C$. anthropophaga maggots in neonates and children in homes with pets.

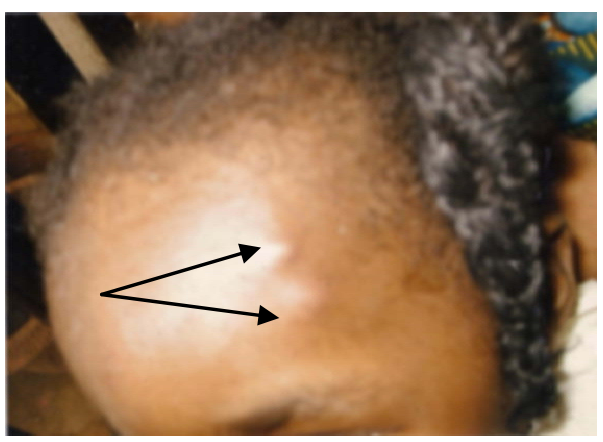

Figure 7. Early symptom of $C$. anthropophaga infection in a 3-year-old female [the two boil-like papules contain 1st instar larvae].

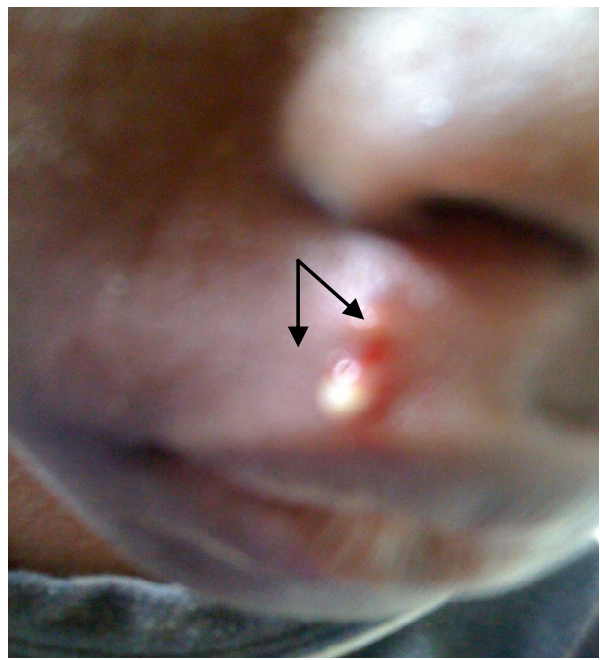

Figure 8. Exit hole of a 3rd instar larva of C. anthropophaga [arrowed were exit hole and serosanguinous fluid].

the reason being that in most villages, toddlers and other older children sat bare on soils and they easily contacted eggs of myiasis-causing agents. Infection from neonates and toddlers was linked with contacts with domestic pets (Figure 6). Early symptoms could be seen in a 3-year-old female who was always in contact with her puppy (Figure 7). An illustration in Figure 8 showed the release of a serosanguinous fluid after the extraction of a third instar maggot of C. anthropophaga. Other reports [8,9] contained cases of cerebral and oral myiases in children.

\section{Conclusions}

Our findings in the present study do not pose any biosecurity risk; because many people who travel to Niger Delta and South-East or any other part of Nigeria were not infected by myiasis-causing agents, therefore there is no fear of myiasis infection for travelers visiting the regions. Some older groups have lived 90 years and above without having any myiasis infection. All we call for here is to create an awareness of the case and to advise that travelers should seek measures of prevention such as ironing of clothes and avoidance of contaminated clothes. Immediate bushes and untrimmed plants around homes and surroundings should be cleared apart from general hygiene and sanitation. Attendants to neonates, nursing mothers, baby handlers and children minders must maintain adequate hygiene over their clothes, beds, beddings and diapers should not be re-used.

\section{REFERENCES}

[1] J. Akhter, S. M. Qadri and A. M. Imam, "Cutaneous Myiasis Due to Dermatobia hominis in Saudis," Saudi Medical Journal, Vol. 21, No. 7, 2000, pp. 689-691.

[2] O. K. Ogbalu, T. G. O. Achufusi and C. Adibe, "Incidence of Multiple Myiasis in Breasts of Rural Women and Oral Infection in Infants from the Human Warble Fly Larvae in the Humid Tropic: Niger Delta,” International Journal of Dermatology, Vol. 45, No. 9, 2006, pp. 10891070. doi:10.1111/j.1365-4632.2006.02983.x

[3] J. G. B. Derraik, A. C. G. Heath and M. Rademaker, "Human Myiasis in New Zealand: Imported and Indigenously-Acquired Cases, the Species of Concern and Clinical Aspects,” Journal of New Zealand Medical Association, Vol. 123, No. 1322, 2010, pp. 21-38.

[4] R. Jelinek, H. D. Nothdurft, N. Rieder and T. Löscher, "Cutaneous Myiasis: Review of 13 Cases in Travellers Returning from Tropical Countries,” International Journal of Dermatology, Vol. 34, No. 9, 1995, pp. 624-626.

[5] S. S. Bapat, "Neonatal Myiasis,” Pediatrics, Vol. 106, No. 1, 2000, p. E6. doi:10.1542/peds.106.1.e6

[6] M. Cetinkaya, H. Ozkan, N. Kosksal, S. Z. Coskun, M. Hacimustaoghi and O. Girlsgin, "Neonatal Myiasis: A Case Report,” The Turkish Journal of Pediatrics, Vol. 50, No. 6, 2008, pp. 581-584.

[7] T. A. McGraw and G. W. Turiansky, "Cutaneous Myiasis," Journal of the American Academy of Dermatology, Vol. 58, No. 6, 2008, pp. 907-926. doi:10.1016/j.jaad.2008.03.014

[8] M. A. Rossi and S. Zucoloto, "Fatal Cerebral Myiasis 
Caused by the Tropical Warble Fly, Dermatobia hominis," The American Journal of Tropical Medicine and Hygiene, Vol. 22, No. 2, 1973, pp. 267-269.

[9] S. S. Dogra and V. K. Mahajan, “Oral Myiasis Caused by
Musca domestica Larvae in a Child,” International Journal of Pediatric Otorhinolaryngology, Vol. 73, No. 11, 2009, pp. 1604-1605. doi:10.1016/j.ijporl.2009.09.015 